\title{
Chapter 12 \\ Towards Displacement-Based Seismic Design of Modern Unreinforced Masonry Structures
}

\author{
Katrin Beyer, S. Petry, M. Tondelli, and A. Paparo
}

\begin{abstract}
Unreinforced masonry (URM) structures are known to be rather vulnerable to seismic loading. Modern URM buildings with reinforced concrete (RC) slabs might, however, have an acceptable seismic performance for regions of low to moderate seismicity. In particular in countries of moderate seismicity it is often difficult to demonstrate the seismic safety of modern URM buildings by means of force-based design methods. Displacement-based design methods are known to lead to more realistic and less conservative results, opening up hence new opportunities for the use of structural masonry. An effective implementation of displacement-based design approaches requires reliable estimates of the structure's force and displacement capacity. This paper contributes to this endeavour by taking a fresh look at the drift capacity of URM walls with hollow clay bricks and mortar joints of normal thickness. It discusses in particular the influence of the size of the test unit and the applied loading history and loading velocity on the drift capacities of URM walls.
\end{abstract}

\subsection{Introduction}

Although unreinforced masonry (URM) construction features excellent properties with regard to sustainability, durability, indoor climate and fire resistance, in most regions of moderate seismicity the total amount of structural masonry in new residential buildings has decreased over the last three decades (Magenes 2006). One reason for this decrease relates to the conservatism of force-based methods which often lead to the situation that URM buildings do not satisfy the seismic

K. Beyer $(\bowtie) \cdot$ S. Petry $\bullet$ M. Tondelli $\bullet$ A. Paparo

Earthquake Engineering and Structural Dynamics Laboratory (EESD), School of Architecture, Civil and Environmental Engineering (ENAC), École Polytechnique Fédérale de Lausanne (EPFL), EPFL ENAC IIC EESD, GC B2 504, Station 18, CH - 1015 Lausanne, Switzerland e-mail: katrin.beyer@epfl.ch 
design check in regions of moderate seismicity. As a result alternative structural systems such as reinforced concrete (RC) walls and gravity frames are used instead. Furthermore, for RC structures already several well developed displacement-based design methods are in place, which yield more realistic and less conservative results than force-based design methods. In order to regain the URM construction's competitiveness with regard to seismic design, displacement-based design methods for URM buildings are necessary. A number of displacement-based design methods for URM structures have recently been proposed. These include applications of the capacity spectrum methods (Fajfar 1999) using inelastic (e.g. Graziotti 2013) or overdamped (e.g. Norda and Butenweg 2011) response spectra or the direct displacement-based design method (Priestley et al. 2007). A summary of these methods can be found in Graziotti (2013).

Displacement-based design methods require the force-displacement response of the structure up to failure as input. With the development of macro-elements representing the nonlinear response of URM walls (Braga and Liberatore 1990; Chen et al. 2008; Belmouden and Lestuzzi 2009; Penna et al. 2013) and their implementation in software packages (Lagomarsino et al. 2013), nonlinear static and dynamic analyses of entire URM buildings have become feasible not only in research but also in engineering practice. Macro-element models are based on pre-defined failure mechanisms and force-displacement relationships of structural components. Next to models for strength and stiffness, the drift capacities of URM walls at horizontal and axial load failure are important input parameters for such models. For RC structures the structural engineer can control the failure mechanism by providing appropriate longitudinal, vertical and confinement reinforcement ratios and layouts. In contrast, most parameters controlling the failure mechanism of URM walls, such as the geometry of the walls, the axial load carried by the walls and the boundary conditions provided by the slabs are defined by architectural considerations or other non-structural requirements (e.g. the thickness of RC slabs depends often on requirements for sound insulation and heating installation). For this reason the ability to predict the nonlinear response of URM buildings forming all kinds of failure mechanisms is a key element towards displacement-based design of URM structures.

Mechanical models for the stiffness and strength of URM walls have been proposed and successfully validated (e.g. Magenes and Calvi 1997). For the deformation capacity of URM walls, comprehensive mechanical models are, however, still lacking. Furthermore, the prediction of the deformation capacity by means of numerical tools remains a challenge although the numerical analysis of URM structures has seen significant advances (for a review see Lourenco 2008; Milani 2012). Numerical models that have been developed for the analysis of URM structures include limit analysis tools (e.g. Milani et al. 2006a, b) which aim at the prediction of failure load and failure mechanism; the simplified micro-models where joints are modelled as interface elements (e.g. Lourenço and Rots 1997; Gambarotta and Lagomarsino 1997a; Snozzi and Molinari 2013); and finite element approaches where masonry is modelled as continuum (e.g. Gambarotta and Lagomarsino 1997b; Zucchini and Lourenço 2002; Facconi et al. 2013). While most of these analysis techniques provide very good approximations of the failure load and often also the failure mechanism, 
Table 12.1 Parameters considered in codes when estimating the drift capacity of URM walls

\begin{tabular}{|c|c|c|c|c|c|}
\hline & $\begin{array}{l}\text { Failure } \\
\text { mode } \\
\text { (shear } \\
\text { vs. flexure) }\end{array}$ & $\begin{array}{l}\text { Slender- } \\
\text { ness ratio } \\
\mathrm{H}_{0} / \mathrm{L}_{\mathrm{w}} \text { or } \\
\mathrm{H} / \mathrm{L}_{\mathrm{w}}\end{array}$ & $\begin{array}{l}\text { Axial } \\
\text { stress } \\
\text { ratio }\end{array}$ & $\begin{array}{l}\text { Moment } \\
\text { profile }\end{array}$ & $\begin{array}{l}\text { Shape of cross } \\
\text { section } \\
\text { (rectangular } \\
\text { vs. flanged) }\end{array}$ \\
\hline EC8-Part 3 (CEN 2005) & $\mathrm{x}$ & $\mathrm{x}$ & & & \\
\hline $\begin{array}{l}\text { German National Annex to EC8-Part } \\
1 \text { (DIN 2011) }\end{array}$ & $\mathrm{x}$ & $\mathrm{x}$ & $\mathrm{x}$ & & \\
\hline Italian code (NTC 2008; MIT 2008) & $\mathrm{x}$ & & & & \\
\hline $\begin{array}{l}\text { New Zealand Standard for seismic } \\
\text { assessment (NZSEE 2006, 2011) }\end{array}$ & $\mathrm{x}$ & $\mathrm{x}$ & & & $\mathrm{x}$ \\
\hline FEMA 306 (ATC 1998) & $\mathrm{x}$ & $\mathrm{x}$ & & & \\
\hline FEMA 273 (ATC 1997) & $\mathrm{x}$ & $\mathrm{x}$ & & & \\
\hline SIA D0237 (SIA 2011) & & & $\mathrm{x}$ & $\mathrm{x}$ & \\
\hline
\end{tabular}

the deformation capacity associated with horizontal load failure (20\% drop in strength) or axial load failure (loss of axial load bearing capacity) is often difficult to predict. Both performance points lie in the post-peak branch where localisation issues render the numerical analyses particularly difficult. The displacement capacity of URM structures is therefore typically determined by drift limits established on the basis of experimental results.

The principal elements in modern URM buildings are URM walls, RC slabs and sometimes spandrel elements consisting of a masonry spandrel and a strip of the RC slab ("composite spandrels"). While the stiffness and strength of RC slabs and composite spandrels are important in order to predict the force-displacement response of the building, their deformation capacity is typically sufficiently large to be non-critical (see experimental results in Beyer and Dazio 2012). Research needs with regard to horizontal elements in URM buildings relate therefore mainly to the effective width of the slab and the stiffness and strength of composite spandrels. First attempts to address these issues are reported in Da Parè (2011), Benaboud (2013) and Marino (2013). The displacement capacity of modern URM buildings is therefore expected to be limited by the URM walls of the building rather than the horizontal elements (Salmanpour et al. 2013). Of all URM walls the first storey walls are expected to be most critical since shear demands are largest for the first storey.

A comprehensive overview on drift capacities in codes is given in Petry and Beyer (2014a). Table 12.1 summarises the different factors considered in these drift capacity models. With the exception of the Swiss guidelines for the seismic assessment of masonry structures (SIA 2011), all drift capacity models are rather similar: The main parameter is the failure mode; typical drift capacities at the "Significant Damage" (SD) limit state are $0.4 \%$ for shear failure and $0.8 \%$ for flexural failure. The origin of these two values is unknown to the authors but it is assumed that they were derived from results of quasi-static cyclic tests. Quasi-static cyclic tests are of course only an approximation of the loading an URM wall is subjected to during a real earthquake. However, most structural engineering 
laboratories do not have the capacity of conducting dynamic tests but many are equipped for quasi-static cyclic tests. As a result, the number of quasi-static tests on URM walls that has been carried out until today clearly outnumbers dynamic tests on URM walls or entire URM buildings. Hence, empirical drift capacity models will have to rely on quasi-static cyclic test results. Using experimental results from isolated URM walls under quasi-static cyclic loading as the basis for empirical drift capacity models raises a number of questions; in particular whether the drift capacity of URM walls is influenced by:

- the size of the test unit?

- the loading history applied to the wall?

- the loading velocity?

This paper attempts to shed some light on these aspects. The paper is limited to the behaviour of URM walls with hollow clay bricks and cement mortar for joints of normal thickness (walls with thin bed joints are not considered).

\subsection{Tests on URM Walls: Influence of Wall Height on Drift Capacity}

Many tests on URM walls have been conducted on specimens with heights between 1.2 and $1.8 \mathrm{~m}$, which corresponds roughly to one half to three quarters of typical storey heights $\mathrm{H}_{\mathrm{s}}$. Apart from restrictions imposed by the test setup, the observation that walls with reduced free height often fail first might have influenced this choice (Fig. 12.1a). In modern URM buildings, however, the window units often reach over the entire storey height and therefore the effective height $\mathrm{H}$ of the walls is equal to the storey height (Fig. 12.1b). In older construction, inner walls correspond also to storey-high walls. Given the range of effective wall heights in real buildings, the question whether the size and therefore height of the test unit influences the drift capacity of URM walls is therefore pertinent.

\subsubsection{Database on URM Wall Tests}

Figure 12.2 shows the distribution of test unit heights from a recently published database on URM wall tests (Petry and Beyer 2014a). A large part of this database stems from the study by Frumento et al. (2009). The database includes walls constructed with full-size clay brick units and cement mortar for joints of normal thickness. The smallest test unit in the database had a height of $\mathrm{H}=1.17 \mathrm{~m}(\approx 0.5$ $\mathrm{H}_{\mathrm{s}}$ ) and the largest test unit had a height of $\mathrm{H}=3.00 \mathrm{~m}$. The database covers therefore well the effective height of walls in real buildings, but it is biased towards the walls with reduced effective heights: out of the 64 tests, 41 tests were conducted on walls with heights smaller than three quarters of a storey height $(\mathrm{H} \leq 2.4 \mathrm{~m})$. 
a

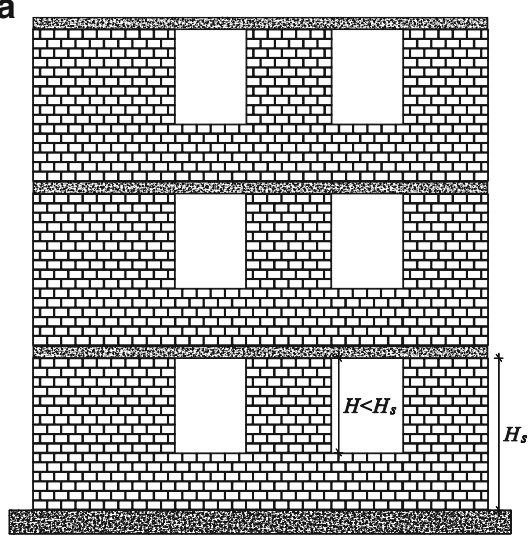

b

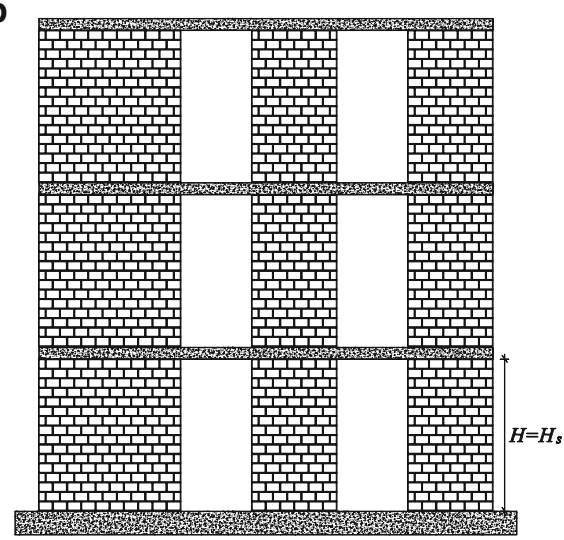

Fig. 12.1 Effective height $\mathrm{H}$ of walls in facades with and without masonry spandrels

a

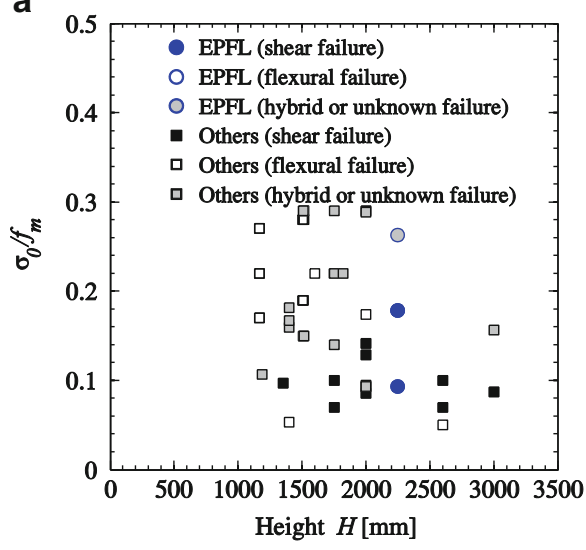

b

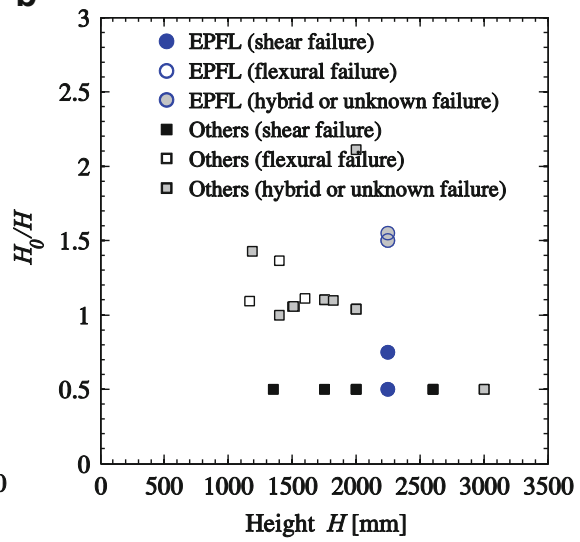

Fig. 12.2 Database on URM walls (Petry and Beyer 2014a): distribution of height $\mathrm{H}$, axial stress ratio $\sigma_{0} / \mathrm{f}_{\mathrm{m}}$ and shear span ratio $\mathrm{H}_{0} / \mathrm{H}$

Most of the walls were tested as cantilever walls $\left(\mathrm{H}_{0} / \mathrm{H} \approx 1.0\right)$ or with fixed-fixed boundary conditions $\left(\mathrm{H}_{0} / \mathrm{H} \approx 0.5\right.$, Fig. 12.2b). Apart from the EPFL-campaign, where the shear span ratio $\mathrm{H}_{0} / \mathrm{H}$ was the key parameter investigated, three further tests featured shear span ratios other than 0.5 or 1.0. In these tests the axial force was applied eccentrically or the height of the top beam was considerable when compared to the rather small test unit. The walls with larger heights than the EPFLwalls were all subjected to fixed-fixed boundary conditions. Seventy percent of the 41 walls smaller than $1.8 \mathrm{~m}\left(\approx 0.75 \mathrm{H}_{\mathrm{s}}\right)$ were tested as cantilevers. The database is therefore dominated by walls that have a height smaller than $\mathrm{H}_{\mathrm{s}}$ and were tested as cantilevers. Deriving drift capacity estimates for codes by averaging the drift 
capacities of all test units in the database that are displaying, for example, a particular failure mode, will inevitably lead to drift capacity estimates representative for this subset. However, it is questionable if short cantilever walls are representative for walls in modern URM structures.

Before closing this section, some reflections on the testing of walls with $\mathrm{H}<\mathrm{H}_{\mathrm{s}}$ : For walls extending only over part of the storey height (Fig. 12.1a), the boundary conditions at the bottom of the wall require particular attention. In the test stand, the test unit is typically placed between concrete or steel beams in order to fix the test unit to the strong floor and apply the horizontal and vertical loads at the top. In a modern building the URM wall is framed by RC slabs. The boundary conditions in laboratories seem therefore representative if full storey high walls are tested. Walls in facades with masonry spandrels (Fig. 12.1a) would be framed by a RC slab at the top and URM masonry at the bottom. The boundary condition at the bottom should therefore be given some consideration since the steel or RC foundation in the laboratory might not be representative. In particular, the confining effect on the bottom mortar joint provided by the steel or RC foundation might be stronger than that of the masonry supporting the wall in real buildings. As a result, the lateral expansion of the brick due to the different Poisson ratios of mortar and brick might be smaller. If the failure mode includes crushing of the URM wall's toe, the confinement provided by the foundation might therefore potentially lead to an increase of the URM wall's drift capacity. To avoid this effect one could consider testing the specimen with an additional brick layer at the base that is fixed to the foundation by a high performance glue.

\subsubsection{A New Empirical Drift Capacity Model for URM Walls}

Figure 12.3a shows the experimentally determined drift capacity $\delta_{\mathrm{u}}$ as a function of the wall height. The drift capacity is the drift capacity associated with a $20 \%$ drop in strength. The figure shows a clear decreasing trend of drift capacity with increasing height. This holds also if the drift capacity is normalised with the shear span ratio $\mathrm{H}_{0} / \mathrm{H}$ accounting for the fact that the drift capacity reduces with reducing shear span ratio (SIA 2011). These plots suggest that the drift capacity of URM walls is influenced by a size effect, as it has first been proposed by Lourenço (1997). Accounting for the effect that the drift capacity of walls reduces with increasing axial load ratio, the following drift capacity equation was recently proposed by Petry and Beyer (2014a):

$$
\delta_{C T}=1.3 \% \cdot\left(1-2.2 \frac{\sigma_{0}}{f_{u}}\right) \cdot \frac{H_{0}}{H} \cdot\left(\frac{2400 m m}{H}\right)^{0.5}
$$

The equation aims at predicting a mean drift capacity as obtained for quasi-static cyclic tests where the test unit is subjected to a constant axial load ratio and a 
a

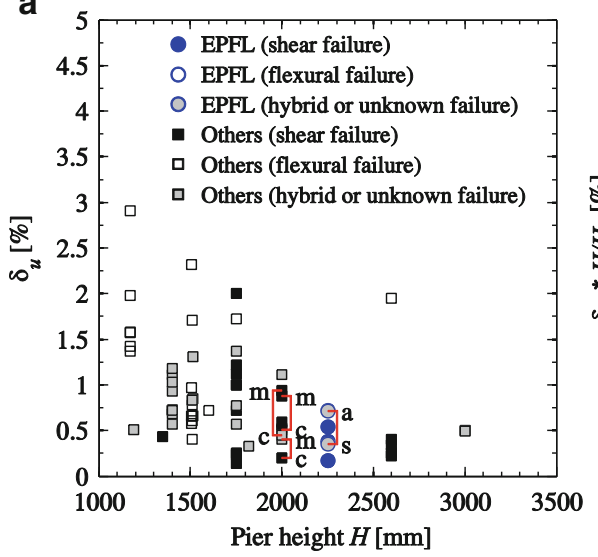

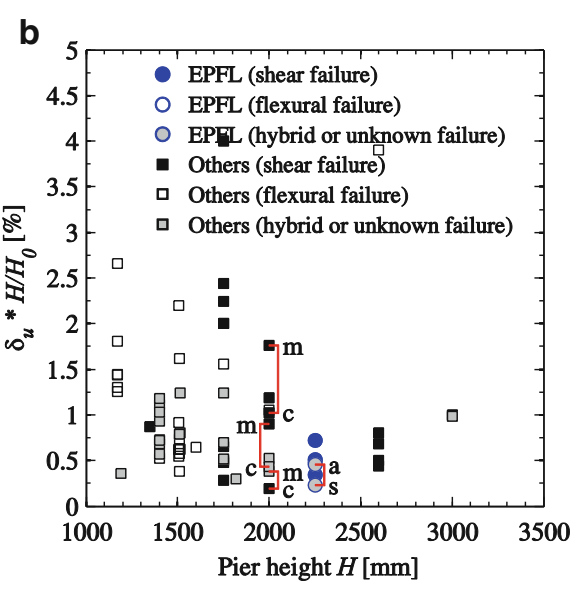

Fig. 12.3 Drift capacity $\delta_{\mathrm{u}}$ (a) and drift capacity normalised with the shear span ratio (b) as a function of the wall height

constant shear span ratio throughout the test. To predict the drift capacities under real earthquake loading, where axial load ratio and shear span ratio might vary and where the wall is subjected to larger strain rates, the drift capacity equation needs to be modified by two correction factors accounting for loading history $\left(\psi_{\mathrm{LH}}\right)$ and strain rate $\left(\psi_{\mathrm{SR}}\right)$ effects respectively. The drift capacity equation at "Near Collapse" limit state therefore becomes:

$$
\delta_{N C}=\delta_{C T} \cdot \psi_{L H} \cdot \psi_{S R}
$$

Section 12.3 investigates effects of the loading history on the drift capacity. In Sect. 12.4 results from static and dynamic tests are compared and conclusions regarding the importance of strain rate effects on the drift capacity are drawn.

\subsection{The Effect of the Loading History on the Drift Capacity}

Since reliable analytical models for predicting the drift capacity of URM walls are currently not available, the drift capacity is typically determined by quasi-static cyclic tests. The main variables that are used in these tests are:

- The axial load ratio,

- The rotational or moment restraint at the top of the wall, and

- The loading history.

In most tests reported in the literature, the axial load ratio was maintained constant throughout the test, the test unit was subjected to either cantilever or 
fixed-fixed boundary conditions, and a loading history with two or three cycles per amplitude level was applied. The total number of cycles until failure was often not a key parameter when defining the loading history. However, for systems susceptible to cumulative damage demands, the number of cycles can influence the force and/or displacement capacity obtained from the quasi-static cyclic test. In current testing practice, in order to capture the evolution of damage limit states, a relatively large number of cycles is often applied. The questions that arise from such testing practice are:

- Does the loading history have an influence on the key parameters of interest, i.e., the effective stiffness, maximum force capacity and drift capacity?

- If it does, is the number of applied cycles representative of the expected cumulative seismic damage demand in the region of interest?

- Are the boundary conditions representative for the critical walls in a structure?

To investigate these questions, first the results from pairs of test units are discussed where one had been subjected to monotonic and one to cyclic loading (Sect. 12.3.1), then loading protocols for cyclic tests on URM walls are reviewed (Sect. 12.3.2) and typical axial force and shear force histories of first storey URM walls are investigated (Sect. 12.3.3).

\subsubsection{Monotonic vs. Cyclic Tests}

When reviewing the test results on URM walls (Sect. 12.2.1), three pairs of tests on URM walls were identified where one wall had been subjected to monotonic loading and the other to cyclic loading. The first two pairs stem from the experimental campaign by Ganz and Thürlimann (1984), the third from Magenes and Calvi (1992). Ganz and Thürlimann applied always 10 cycles per amplitude level, which from today's point of view is certainly not representative since it exceeds considerably the number of cycles imposed by an earthquake. The total number of cycles applied until failure was 58 for W6 and 61 for W7. Magenes and Calvi applied a loading history which corresponds in many respects already to today's standard for URM wall testing. Until failure, the cyclic loading history comprised $\sim 6$ cycles.

Table 12.2 summarises the three main properties of the envelope curves in Fig. 12.4, i.e. the effective stiffness, the maximum force and the drift capacity. The effective stiffness is the secant stiffness at $0.75 \mathrm{~F}_{\max }$ and the drift capacity the drift at which the force had dropped to $0.8 \mathrm{~F}_{\max }$. For the cyclic tests, the effective stiffness $\mathrm{K}_{\mathrm{C}}$ and the strength $\mathrm{F}_{\max , \mathrm{C}}$ are taken as average values obtained for the positive and negative loading direction. The drift capacity $\delta_{\mathrm{u}, \mathrm{C}}$, on the contrary, is defined as the minimum of the two values (see Frumento et al. 2009). From the three parameters, the maximum force is the one which is the least affected by the loading scheme. The largest influence of the loading history is observed for the drift capacity, which is in average twice as large for monotonic tests than for quasi-static cyclic tests. Somewhat surprising is the consistently larger stiffness for cyclic tests 
Table 12.2 Monotonic vs. cyclic loading: comparison of effective stiffness, maximum force and drift capacity

\begin{tabular}{|c|c|c|c|c|c|c|c|c|c|}
\hline & \multicolumn{3}{|c|}{ Cyclic test } & \multicolumn{3}{|c|}{ Monotonic test } & \multicolumn{3}{|c|}{ Cyclic/monotonic } \\
\hline & $\begin{array}{l}\mathrm{K}_{\mathrm{C}} \\
{[\mathrm{kN} / \mathrm{m}]}\end{array}$ & $\begin{array}{l}\mathrm{F}_{\max , \mathrm{C}} \\
{[\mathrm{kN}]}\end{array}$ & $\begin{array}{l}\delta_{\mathrm{u}, \mathrm{C}} \\
{[\%]} \\
\end{array}$ & $\begin{array}{l}\mathrm{K}_{\mathrm{M}} \\
{[\mathrm{kN} / \mathrm{m}]}\end{array}$ & $\begin{array}{l}\mathrm{F}_{\max , \mathrm{M}} \\
{[\mathrm{kN}]}\end{array}$ & $\begin{array}{l}\delta_{\mathrm{u}, \mathrm{M}} \\
{[\%]}\end{array}$ & $\begin{array}{l}\mathrm{K}_{\mathrm{C}} / \mathrm{K}_{\mathrm{M}} \\
{[-]}\end{array}$ & $\begin{array}{l}\mathrm{F}_{\max , \mathrm{C}} / \\
\mathrm{F}_{\max , \mathrm{M}}[-]\end{array}$ & $\begin{array}{l}\delta_{\mathrm{u}, \mathrm{C}} / \delta_{\mathrm{u}}, \\
\mathrm{M}[-]\end{array}$ \\
\hline W1 \& W6 & 178 & 256 & 0.45 & 127 & 266 & 0.94 & 1.40 & 0.96 & 0.48 \\
\hline W2 \& W7 & 218 & 496 & 0.20 & 163 & 479 & 0.40 & 1.34 & 1.03 & 0.50 \\
\hline $\begin{array}{c}\text { MI1m \& } \\
\text { MI1 }\end{array}$ & 98 & 263 & 0.28 & 66 & 258 & 0.78 & 1.49 & 1.02 & 0.35 \\
\hline $\begin{array}{l}\text { Mean } \\
\text { ratio }\end{array}$ & & & & & & & 1.41 & 1.00 & 0.44 \\
\hline
\end{tabular}

than for monotonic tests. The authors do not have an explanation for this observation. It must be assumed that it is linked to the alternating loading direction since mortar strengths and age of the test units at the day of testing were very similar for all test units by Ganz and Thürlimann; Magenes and Calvi did not report mortar strengths for the individual walls.

Despite the admittedly very limited data set, this comparison of monotonic vs. cyclic test results suggests that the loading history is not important if one is only interested in the force capacity of the URM wall. It becomes, however, significant if the displacement capacity and possibly also the effective stiffness are of interest. When results of quasi-static cyclic tests of URM walls are used to derive drift capacity limits for displacement-based design, attention should therefore be paid to the loading history that was applied in the test.

\subsubsection{Loading Protocols for Cyclic Tests}

For systems susceptible to strength and stiffness degradation, the strength and deformation obtained from quasi-static cyclic tests will depend on the imposed loading history. Hence, the obtained capacities are directly related to imposed demands. For this reason, loading protocols for quasi-static cyclic tests on URM walls should be given some consideration.

Tomazevic and co-workers $(1996,2000)$ addressed loading history effects on the response of reinforced masonry walls displaying a flexural failure mode but until today no systematic investigation on the influence of different cyclic loading protocols on the drift capacity of URM walls was carried out. The effect of the number of cycles on the performance of URM walls can therefore only be inferred indirectly via the comparison of the envelopes of first cycles with envelopes of second or third cycles. The walls of the EPFL test series were subjected to two cycles per drift level. Figure 12.5 shows for three of these walls the envelopes of the first and second cycles. The three walls developed different failure mechanisms: PUP2 a 

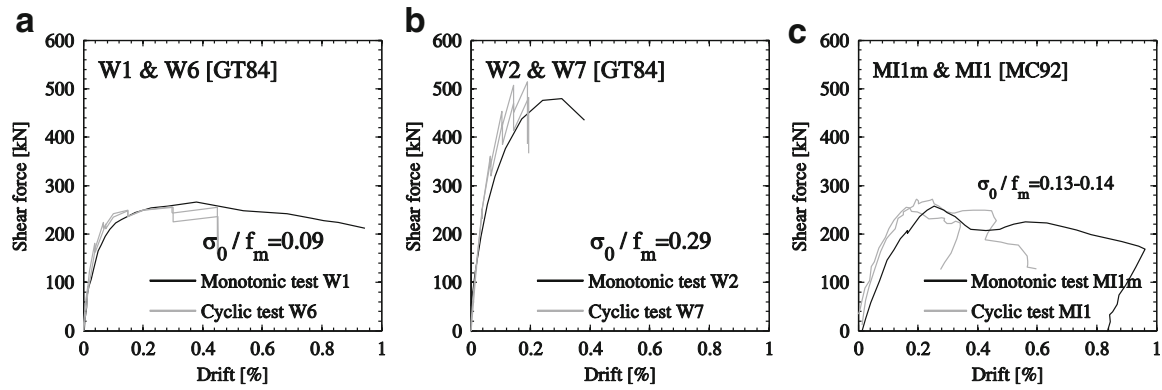

Fig. 12.4 Monotonic vs. cyclic loading: comparison of force-displacement envelopes

diagonal shear failure, PUP3 a rocking failure and PUP4 a hybrid failure mode. Up to a certain point close to the peak force, the difference between first and second cycle envelopes is negligible. As soon as the difference becomes significant, failure is imminent. The envelopes of the first and second cycle start to diverge once the first limit state inducing irreversible damage has been reached, i.e. failure of the compression zone (Limit State (LS) F3, Petry and Beyer 2014c) or concentration of shear deformations in a single diagonal crack (LS S3). Hence, before these limit states, the behaviour of the URM walls is rather insensitive to the loading history while the remaining drift capacity after one of these limit states have been reached appears strongly dependent on the loading history. Since at these limit states the maximum force capacity has already been reached, the force capacity does not seem sensitive to the loading history, while the loading history is expected to influence the drift capacity.

Since the quantitative effect of the loading history on the drift capacity is unclear, a loading history should be applied, that represents the seismic demand of the geographical region of interest as closely as possible. Existing standardized loading protocols were derived for regions of high seismicity (e.g. ATC-24 1992; FEMA-461 2007); one even specifically for masonry structures (Porter 1987). Krawinkler (2009), however, points out that the latter imposes even for high seismic regions far too many cycles. Most research projects on URM structures address construction practice in low to moderate seismic countries and hence loading protocols should be applied that impose fewer cycles until failure. Figures 12.6a and b show examples of loading protocols that represent the cumulative damage demands imposed in regions of high and regions of low to moderate seismicity for a hazard level with a $2 \%$ probability of exceedance in 50 years (Mergos and Beyer 2014). The loading protocols were derived from nonlinear time history analysis results of a large set of single degree of freedom systems that reflect the fundamental properties of typical structural systems. To avoid excessive conservatism for particular types of structures, a set of protocols was developed that account for the different cumulative demands as a function of the structural type, fundamental period, number of cycles per amplitude level and the seismicity. 

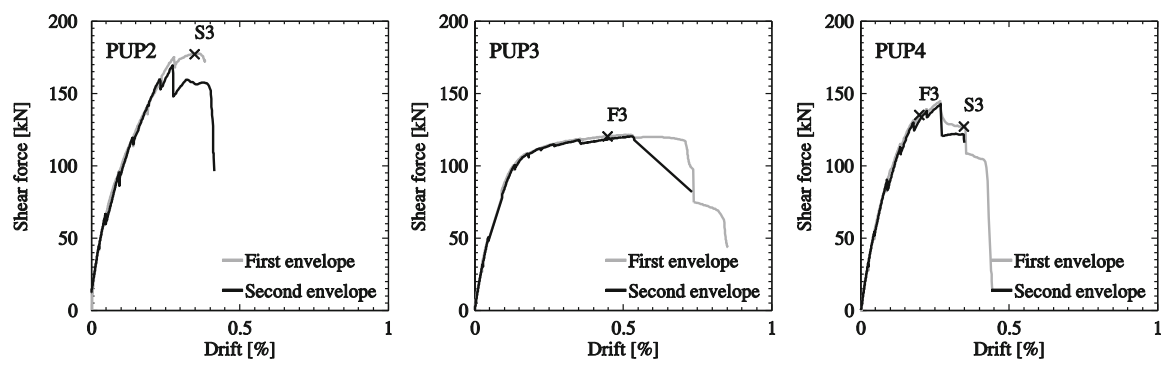

Fig. 12.5 Comparison of first and second envelopes of quasi-static cyclic tests (Petry and Beyer 2014b)
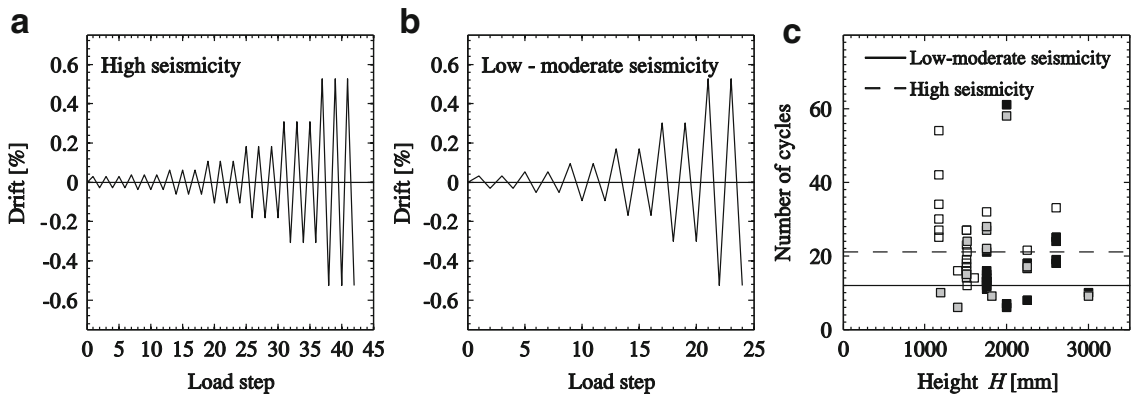

Fig. 12.6 Influence of the seismicity on a representative load protocol: drift controlled load histories for quasi-static cyclic testing of URM walls expected to fail in shear for which the cumulative cyclic demand is representative for countries of high seismicity (a) and low - moderate seismicity (b). Number of cycles applied in quasi-static cyclic tests of URM walls (c)

The loading protocols shown in Fig. 12.6a, b reflect the cumulative damage demands on shear dominated URM structures with a fundamental period $\mathrm{T}=0.2 \mathrm{~s}$. In this example, a loading history with three cycles per drift amplitude was chosen for the high seismicity case and with two cycles per drift amplitude for the low-moderate seismicity case. The expected drift capacity at the "Near Collapse" limit state was estimated according to EC8-Part 3 (CEN 2005). One sees that the number of cycles imposed on URM structures in high seismicity regions is approximately twice as large as in regions of low-moderate seismicity (21 cycles vs. 12 cycles). Figure 12.6c shows the number of cycles applied to the test units of the database (Sect. 12.2.1). For most tests the number could only be roughly estimated from hysteresis plots. However, the figure clearly shows that in many tests the number of applied cycles exceeds what would be representative for the demand on URM buildings in countries of low-moderate seismicity. 


\subsubsection{Inner Walls vs. Outer Walls}

In an URM building with strong RC slabs, most of the damage concentrates typically in the first storey of the building (Paulay and Priestley 1992; Paparo and Beyer 2014). Quasi-static cyclic tests should therefore represent the boundary conditions of the first storey walls. Among these, the demands on inner and outer walls differ significantly with regard to axial forces and shear spans (Petry and Beyer 2014a).

Figure 12.7 shows the axial force and base shear of an outer and an inner wall for a 4-storey example building. The structure was analysed using the macro element software Tremuri (Lagomarsino et al. 2013). The input ground motion was an artificial record from the study by Priestley and Amaris (2002). In the analysis the walls were not assigned an ultimate drift capacity. The analysis results show that the inner wall is subjected to an axial force which is relatively constant throughout the duration of the earthquake and its shear force - drift hysteresis is fairly symmetric about the origin. The seismic behaviour of such a central wall seems therefore well represented in quasi-static cyclic tests where a constant axial force and a constant shear span ratio are applied to the wall.

The picture is different if an outer wall is considered: In the left wall, the axial force increases when the structure is pushed towards the left while it decreases when the structure moves towards the right. As a result, the maximum base shear is larger for the negative loading direction than for the positive loading direction. Due to the decrease in displacement capacity with increasing axial force (Lang 2002), outer walls fail therefore typically in the loading direction where the axial force increases in the wall (see, for example, Beyer et al. 2014). The question arises how the drift capacity of walls subjected to such asymmetric boundary conditions for the two loading directions compares to the drift capacity of walls subjected to the same boundary conditions in the two loading directions.

The behaviour of outer walls is less well represented by standard test configurations for URM walls and the question arises how well their displacement capacity can be estimated from standard tests. A preliminary attempt to investigate this topic has been carried out within the EPFL-series on URM walls. The sixth test PUP6 represented boundary conditions of an outer wall: It approached for the positive loading direction those of PUP5 and for the negative loading direction those of PUP4. Figure 12.8 shows the applied axial load and shear span ratio as function of the applied horizontal load and drift.

In the negative loading direction PUP6 was subjected to larger axial forces than in the positive loading direction. Hence, the wall was expected to fail for loading in the negative direction where the boundary conditions of PUP4 were approached. For horizontal and vertical load failure, the drift capacities of PUP6 were 2.0 and 1.6 times larger than those of PUP4 (Figure 12.8), i.e., the results suggest that the displacement capacity of an asymmetrically loaded wall is about twice as large as the displacement capacity of a symmetrically loaded wall. The weakest zone in symmetrically loaded walls failing in diagonal shear is the zone where the two 

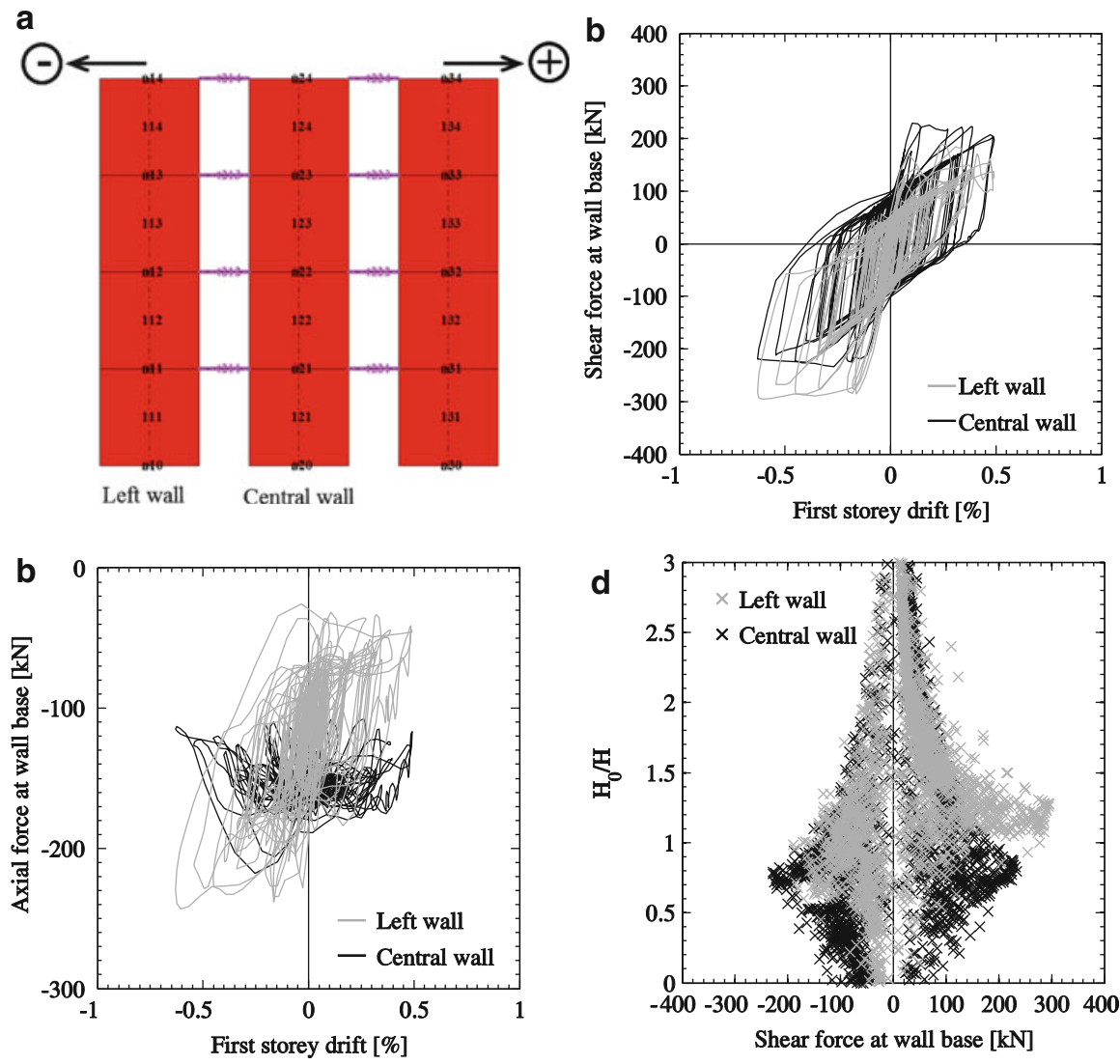

Fig. 12.7 Demand on inner and outer first storey walls in terms of axial force (a), shear force (b) and shear span ratio $\mathrm{H}_{0} / \mathrm{H}(\mathbf{c})$

diagonal cracks intersect and failure of this zone tends to trigger horizontal load and axial load failure. In asymmetrically loaded walls that develop a flexural mechanism in one and a shear mechanism in the other direction, such zone does not exist. If the wall develops a shear mechanism for both directions, the shear crack is typically much smaller for one direction than for the other. As a result, this heavily disaggregated zone at the intersection of two diagonal shear cracks, which often controls the drift capacity of symmetrically loaded walls, does not exist for asymmetrically loaded walls. Note that for PUP6 the definition of the critical loading direction was less clear than for walls in most real buildings. While the axial load was larger for the negative loading direction, the shear span ratio was smaller for the positive loading direction. As a result, the maximum shear forces were rather similar for the two loading direction and the onset of failure occurred in fact for the positive loading direction (Petry and Beyer 2014a). 

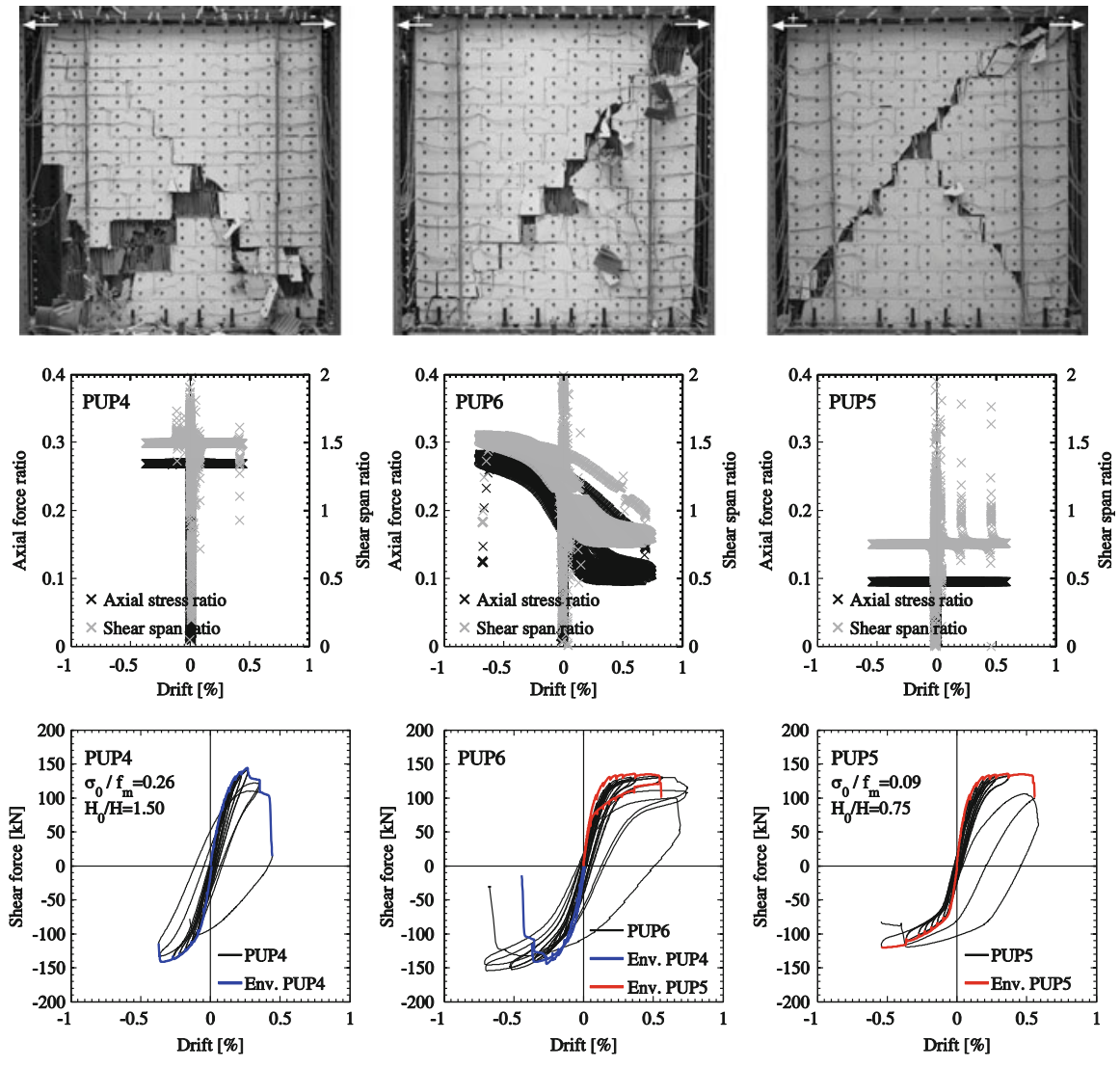

PUP4

PUP6
Asymmetrically loaded

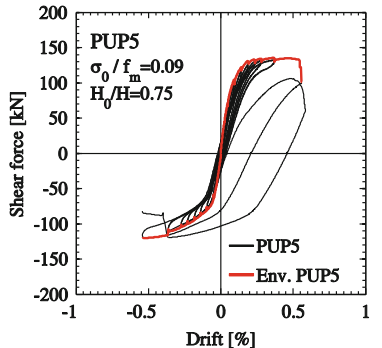

PUP5

Symmetrically loaded

Fig. 12.8 Results of quasi-static cyclic tests on symmetrically (PUP4, PUP5) and asymmetrically (PUP6) loaded walls: failure mode, axial load ratio, shear span ratio and hystereses (Petry and Beyer 2014a)

\subsubsection{Conclusions on Loading History}

For systems susceptible to cumulative damage demands, the system's force and/or displacement capacities are a function of the imposed cumulative demand, i.e., the number of cycles until failure is attained. When determining these parameters from quasi-static cyclic tests, the applied horizontal loading history needs to be given due attention. Until today no systematic study of the effect of the loading history on the force and displacement capacity of URM walls has been carried out and therefore a final expression for the correction accounting for load history effects cannot be proposed. The following paragraphs summarise the preliminary trends identified in Sects. 12.3.1, 12.3.2, and 12.3.3. 
Cyclic tests resulted in only half the drift capacity as monotonic tests but the loading regime had no effect on the force capacity. The reduction in drift capacity under cyclic loading is linked to the cumulative damage induced by the cycles that are applied after the limit states F3 (failure of the compressed zone) or S3 (concentration of shear deformations in a single diagonal crack) have been attained. A study comparing the behaviour of walls subjected to different cyclic loading histories could not be found in the literature. To get a first idea of the impact of the number of cycles on the force-displacement response, envelopes of first and second cycles were compared. As for the monotonic and cyclic tests, the difference between these envelopes became only significant once the limit state F3 or S3 have been passed. Since these limit states are attained after the strength plateau has been reached, only the drift capacity but not the force capacity is expected to be affected by the loading history. When determining quantities relevant for force-based design from quasi-static cyclic tests, the loading history is therefore of lesser importance. However, when drift capacity estimates are sought, due attention should be given to the number of cycles applied until failure of the wall.

Since at present the exact effect of the loading history on the drift capacity of URM walls is unknown, a loading history should be applied which reflects the expected cyclic demand on the wall during a "Near Collapse" scenario. Attention should be paid to

- The number of cycles imposed until failure,

- The boundary conditions, i.e. axial load ratio and shear span ratio,

- Whether the boundary conditions are the same for the positive and negative loading direction.

The number of cycles a system is subjected to depends on its properties (fundamental period, hysteretic behavior) and the seismicity of the case study region. URM structures are mainly constructed in low-moderate seismicity regions and therefore fewer cycles than for high seismicity regions should be applied.

Quasi-static cyclic tests applying a constant axial force to the specimen that is tested as cantilever or with fixed-fixed boundary conditions will remain the standard test since the boundary conditions are well defined and within the capabilities of many structural engineering laboratories around the world. Boundary conditions of URM walls in real buildings are, however, more diverse. This applies in particular to the shear span ratio, which can vary approximately between 0.5 and 2.0 $\mathrm{H}$ for URM buildings with RC slabs and the symmetry of the boundary condition for the positive and negative loading direction. While symmetric cycles with constant shear span and axial load ratio approximate the demand on inner walls typically well, this does not hold for outer walls. For the latter the axial load and shear span ratios fluctuate with the loading direction. A first investigation into the effect of such asymmetric loading histories showed that the drift capacity of asymmetrically loaded walls might be twice as large as that of symmetrically loaded walls, i.e., similar to the drift capacities obtained from monotonic load tests. For such walls a correction factor of $\psi_{\mathrm{LH}}=2$ is therefore proposed (Eq. (12.1), Sect. 12.2.2). 


\subsection{Quasi-static vs. Dynamic Tests}

It is likely that quasi-static cyclic tests will remain the standard tests for determining drift capacities of URM walls. However, the actual purpose is to find drift capacity estimates for walls subjected to earthquake loading. During an earthquake, URM walls are subjected to strain rates that are approximately 1,000 times higher than during quasi-static tests. To link static to dynamic drift capacities, strain rate effects on the drift capacity need to be quantified and expressed by means of the correction factor $\psi_{\mathrm{SR}}$ (Sect. 12.2, Eq. (12.2)).

Williams and Scrivener (1974) and Tomazevic et al. (1996) investigated strain rate effects on reinforced masonry. Both reported similar drift capacities for static and dynamic tests. Abrams (1996) compared the behaviour of unreinforced masonry structures under static and dynamic loading and concluded that the loading history affected the cracking pattern. However, he acknowledges that the structures were tested at different scales with different construction materials and different restraints provided to the flexible diaphragms, which made it difficult to compare them one-to-one. Elgawady et al. (2004) compared the results of URM walls with and without GFRP wrapping under static and dynamic loading. However, the shake table tests were stopped prematurely and hence no conclusions regarding the drift capacities at horizontal and vertical load failure under dynamic loads were possible. A numerical study by Snozzi and Molinari (2013) showed that the strength of URM walls is larger when subjected to higher strain rates due to a more diffuse cracking pattern. However, this study did not yield any information regarding the effect of the strain rate on the deformation capacity since the bricks were modelled as elastic.

This section addresses the effect of strain rates on drift capacities by comparing the maximum drifts attained in quasi-static cyclic tests on walls to the maximum drifts attained in a shake table test of a 4-storey building (Beyer et al. 2014; Tondelli et al. 2014). Both walls and building were constructed at half scale using the same, special fabricated half-scale bricks (Petry and Beyer 2014d). The walls had similar but not identical dimensions. The walls tested under quasi-static cyclic loading were $1.00 \mathrm{~m}$ long and $1.11 \mathrm{~m}$ high and had a rectangular cross section. The walls of the building tested on the shake table were $1.55 \mathrm{~m}$ long and $1.40 \mathrm{~m}$ high and had small flanges at the wall ends in order to increase the out-of-plane stability of the walls.

The comparison between shake table test results of an entire building and quasistatic cyclic tests will always be approximate since the exact boundary conditions and loading history of the walls in the building are unknown. In addition, the geometries of the two sets of walls differ slightly. However, in the absence of tests where only the loading velocity but none of the other parameters was varied, the comparison of results from a shake table test and quasi-static cyclic tests might allow to shed some new light on the effect of strain rates on the deformation capacity of URM walls. The following sections investigate the demand on the walls in the building on the basis of nonlinear analysis (Sect. 12.4.1), analyse the drift capacities obtained from quasi-static cyclic tests (Sect. 12.4.2) and compare 
drifts attained in the shake table test to the drift capacities from quasi-static cyclic tests (Sect. 12.4.3). Section 12.4.4 gives recommendations for the choice of the correction factor $\psi_{\mathrm{SR}}$ that accounts for strain rate effects (Eq. (12.2)).

\subsubsection{Shake Table Test}

The building tested on the shake table was a 4-storey structure with URM walls and RC walls. The building was subjected to uni-directional shaking and tested at the TREES laboratory in Pavia (Italy). The shaking induced in-plane loading in the facade shown in Fig. 12.9. Detailed information on the shake table test will shortly be published (Beyer et al. 2014) and the data collected during the test shared (Tondelli et al. 2014).

It is assumed that the drift capacity of the URM walls is a function of the axial load ratio, the shear span ratio and the height of the wall (see Eq. (12.1)). Hence, to estimate the drift capacities of the first storey walls, the axial load ratios and shear span ratios need to be estimated. Since the internal forces cannot be measured during a shake table test, they need to be estimated from numerical analyses. Since the building was symmetric about its longitudinal axis, a pushover analysis of a 2D simplified micro model of the facade using the software package Atena (Cervenka et al. 2010) was carried out. Details on this analysis and a comparison of experimental and numerical results are given in Beyer et al. (2014). Figures 12.10 and 12.11 show the internal force distribution in the façade when the wall is pushed towards the left (increase in axial forces in the left URM wall) and the right (increase in axial force in the RC wall). Assuming that all axial forces are carried by the in-plane loaded walls, the first storey walls are subjected to axial forces of $137 \mathrm{kN}$ (left wall) and $104 \mathrm{kN}$ (central wall), which correspond to axial load ratios of 0.16 and 0.12 , respectively.

During the last two runs (Run 8 and 9) the building reached for both directions of loading the inelastic range and therefore it can be assumed that the internal force distribution at peak displacements was similar for both runs. The plots in Figs. 12.10 and 12.11 show the internal forces at $\delta_{\text {avg }}=-0.26 \%$ and $0.32 \%$ respectively. These average drifts over the height of the building correspond to the peak drifts attained in negative and positive direction during Run 8. Table 12.3 summarises the axial stress ratios and shear span ratios of the two first storey walls for the positive and negative loading direction. The following section compares for these two URM walls the drift capacities obtained from static and dynamic tests. 

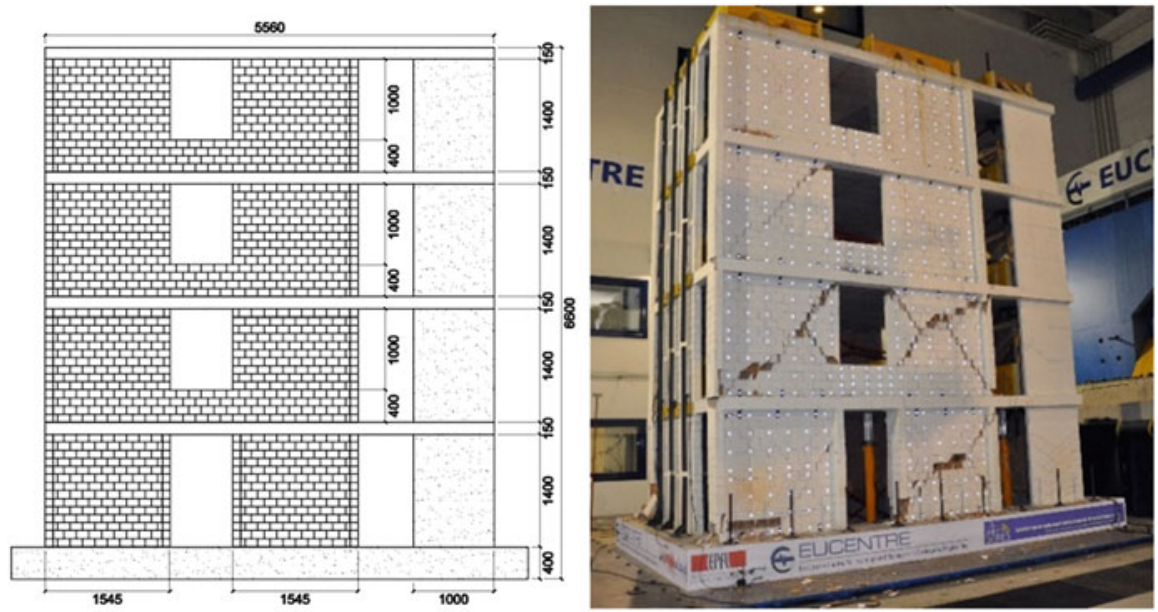

Fig. 12.9 Shake table test unit at half scale

a Shear forces $[\mathrm{kN}]$

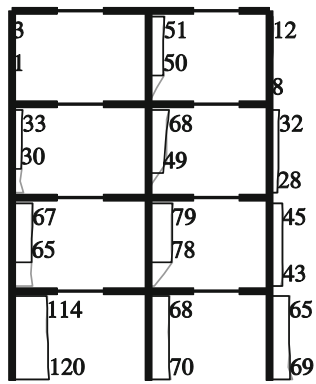

b Bending moments $[\mathrm{kNm}]$

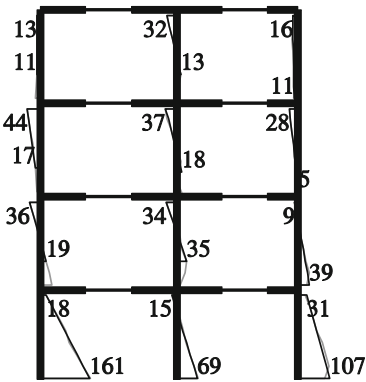

C Axial forces $[\mathrm{kN}]$

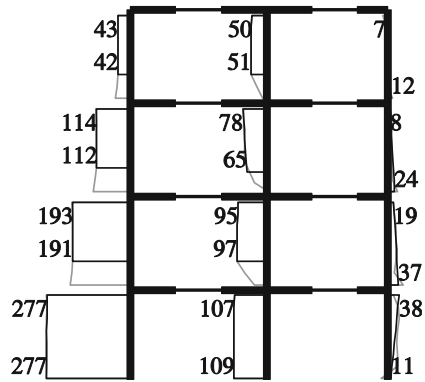

Fig. 12.10 Numerical model of shake table test unit: internal forces for negative loading direction at $\delta_{\text {avg }}=-0.26 \%$

\subsubsection{Drift Capacities Estimated from Quasi-static Cyclic Tests}

To prepare the shake table test and to decide in particular on the model brick to be used, five out of the six quasi-static cyclic tests on full-scale walls were replicated at half-scale (Petry and Beyer 2014d). Figure 12.12 shows the test setups for the two test series. The half-scale walls reflected the behaviour of the full-scale walls very well in terms of stiffness, strength, drift at maximum horizontal force, drift capacity at horizontal load failure and the failure mode. Only with regard to the drift capacity at axial load failure led the half-scale walls to values which were significantly larger 
a Shear forces $[\mathrm{kN}]$

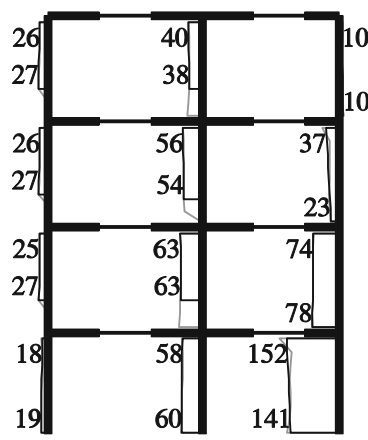

b Bending moments $[\mathrm{kNm}]$

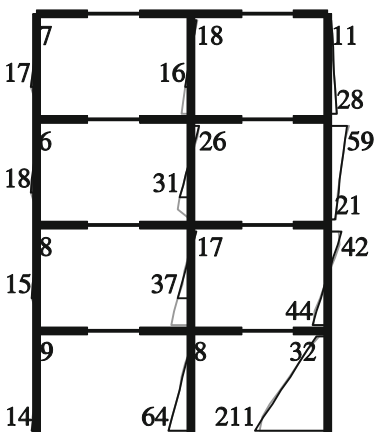

C Axial forces $[\mathrm{kN}]$

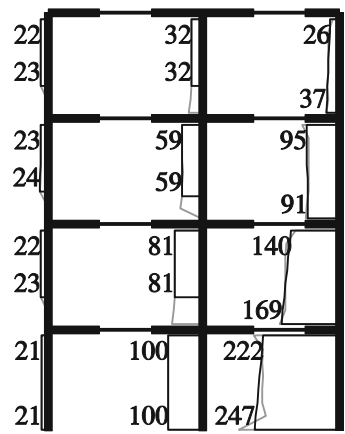

Fig. 12.11 Numerical model of shake table test unit: internal forces for positive loading direction at $\delta_{\text {avg }}=0.32 \%$

Table 12.3 Demand on first storey walls based on results of numerical model and estimated drift capacities based on quasi-static cyclic tests

\begin{tabular}{|c|c|c|c|c|c|}
\hline \multirow[b]{2}{*}{ First storey } & \multicolumn{2}{|c|}{$\begin{array}{l}\text { Negative } \\
\text { loading } \\
\text { direction }\end{array}$} & \multirow{2}{*}{$\begin{array}{l}\text { Negative loading direction but drift values } \\
\text { from test unit with max. axial stress ratio } \\
\text { Outer wall }\end{array}$} & \multicolumn{2}{|c|}{$\begin{array}{l}\text { Positive } \\
\text { loading } \\
\text { direction } \\
\end{array}$} \\
\hline & $\begin{array}{l}\text { Outer } \\
\text { wall }\end{array}$ & $\begin{array}{l}\text { Inner } \\
\text { wall }\end{array}$ & & $\begin{array}{l}\text { Outer } \\
\text { wall }\end{array}$ & $\begin{array}{l}\text { Inner } \\
\text { wall }\end{array}$ \\
\hline $\mathrm{N}[\mathrm{kN}]$ & 277 & 109 & 277 & 21 & 100 \\
\hline$\sigma[\mathrm{MPa}]$ & 1.94 & 0.76 & 1.94 & 0.15 & 0.70 \\
\hline$\sigma / \mathrm{f}_{\mathrm{m}}$ & 0.34 & 0.14 & 0.34 & 0.03 & 0.12 \\
\hline $\mathrm{H}_{0}=\mathrm{M} / \mathrm{V}[\mathrm{m}]$ & 1.34 & 0.99 & 1.34 & 0.74 & 1.07 \\
\hline $\mathrm{H}_{0} / \mathrm{H}$ & 0.96 & 0.70 & 0.96 & 0.53 & 0.76 \\
\hline $\mathrm{R}$ & 0.85 & 0.85 & 0.85 & 0.85 & 0.85 \\
\hline$\psi_{\mathrm{SR}}$ & 2.0 & 1.0 & 2.0 & 1.0 & 1.0 \\
\hline$\delta_{\text {peak }}[\%]$ & 0.06 & 0.24 & 0.36 & 0.28 & 0.29 \\
\hline$\delta_{\mathrm{u}}[\%]$ & -0.26 & 0.40 & 0.59 & 0.51 & 0.49 \\
\hline$\delta_{\max }[\%]$ & -0.26 & 0.58 & 0.76 & 0.73 & 0.71 \\
\hline
\end{tabular}

than those of the full-scale walls. Figure 12.13 shows the comparison of the drift capacities at the three performance limit states including linear trend lines.

The drift capacities of the first storey walls of the building tested on the shake table are estimated from these linear trend lines in Figure 12.13 for the axial stress and shear span ratios obtained from the pushover analyses (Table 12.3). In addition, the following two effects are considered:

- The walls in the building are somewhat larger than the walls tested under quasistatic cyclic loads. To account for the size effect discussed in Sect. 12.2, the drift 

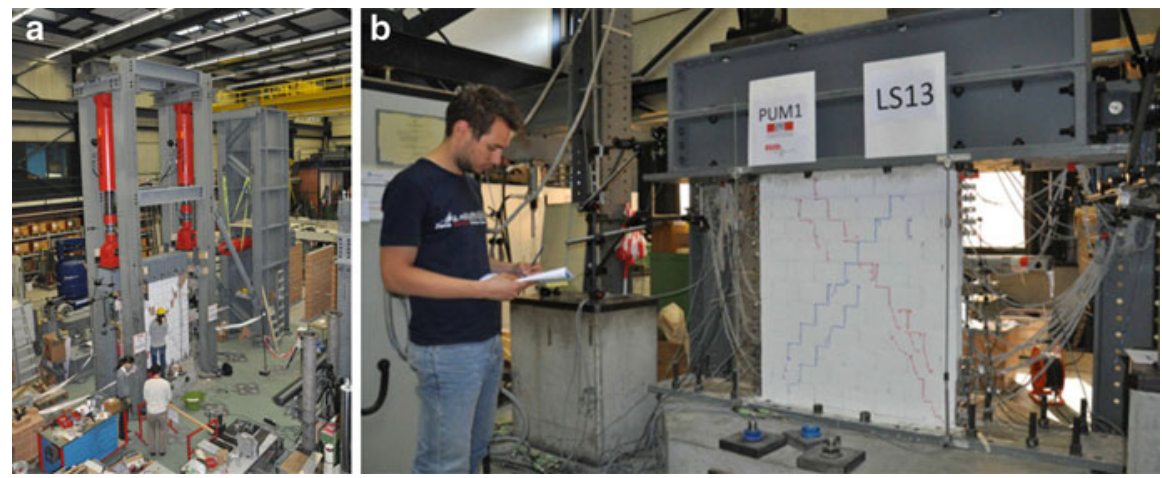

Fig. 12.12 Test setups for quasi-static cyclic tests on full-scale (a) and half-scale (b) walls
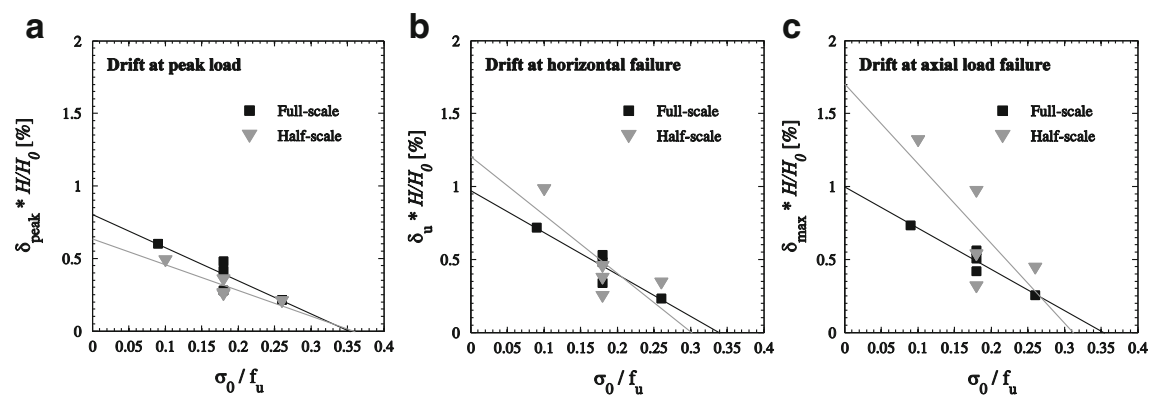

Fig. 12.13 Drift values of full- and half-scale walls at peak load (a), horizontal load failure (b), and axial load failure (c)

capacities obtained from the quasi-static cyclic tests are reduced by the following factor (see Eq. (12.1)):

$$
R=\left(\frac{1110 m m}{1400 m m}\right)^{0.5}=0.89
$$

- For the outer wall, when loaded in the negative direction, the correction factor accounting for the load history was assumed as $\psi_{\mathrm{LH}}=2$ (see Eq. (12.2) and Sect. 12.3.3). For all other walls/loading directions $\psi_{\mathrm{LH}}=1$ was assumed.

The correction factor for strain rate effects $\psi_{\mathrm{SR}}$ was set to unity. Table 12.3 reports the resulting drift capacities at peak load $\left(\delta_{\text {peak }}\right)$, horizontal load failure $\left(\delta_{\mathrm{u}}\right)$ and axial load failure $\left(\delta_{\max }\right)$. One problem becomes immediately apparent: The axial load ratio of the outer wall for loading in the negative direction is outside the range of axial load ratios covered in the quasi-static cyclic tests. With the linear trend model the drift capacities at this axial load ratio are negligible or even negative. This is of course not meaningful. Furthermore, it is probable that the 
axial load ratio in the outer wall was overestimated by the 2D model which neither included out-of-plane walls nor the flanges of the in-plane loaded walls. For these reasons the drift capacities obtained for the wall that had been subjected to the largest axial stress ratio $\left(\sigma / \mathrm{f}_{\mathrm{m}}=0.27\right)$ will be used to derive the drift capacity of the outer wall for the negative loading direction. As outlined above, the reduction factor $\mathrm{R}=0.89$ accounting for the size effect and the correction factor $\psi_{\mathrm{LH}}=2$ for the load history effect will be considered. The resulting drift capacity of an outer wall is therefore computed as follows:

$$
\delta=\delta_{P U M 4} \cdot \frac{\left(H_{0} / H\right)}{\left(H_{0} / H\right)_{P U M 4}} \cdot R \cdot \psi_{L H}
$$

The drifts of PUM4 at peak load, horizontal load failure and axial load failure were $0.31 \%, 0.52 \%$ and $0.67 \%$ respectively; the shear span ratio was 1.5 . The drift capacities resulting for the outer wall and the negative loading direction are summarized in the central column of Table 12.3.

\subsubsection{Comparison of Drift Histories from Shake Table Test with Drift Capacities from Quasi-static Cyclic Tests}

The shake table test unit was subjected to nine runs; only the last two induced significant damage. In the following, the drift histories measured at the centre line of the outer and inner URM walls of the first storey are compared to the drift limits derived in the previous section from quasi-static cyclic tests (Table 12.3). For details of the computation of the drift histories from the optical measurements see Beyer et al. (2014).

After Run 8 the damage in the URM panels started concentrating in one diagonal crack. From quasi-static cyclic tests on URM walls it is known that this indicates that the post peak branch has been reached and failure is rather imminent (Petry and Beyer 2014d). The drift histories of the outer and inner wall exceeded just the drift limits corresponding to the peak force (Fig. 12.14). Hence, for this limit state, the drift limits derived from the quasi-static cyclic tests seem to correspond well with the observed behaviour of the shake table test unit.

In Run 9 all walls of the first and second storey lost their axial load bearing capacity. Also this observation agrees with the findings when comparing drift histories from the shake table test with the drift limits obtained from quasi-static cyclic tests (Fig. 12.15): Both walls exceeded the drift limit for axial load failure for the negative loading direction. The inner wall touched the same limit also for the positive loading direction. Figure 12.16 shows the damage of the URM walls after this final run. 
a
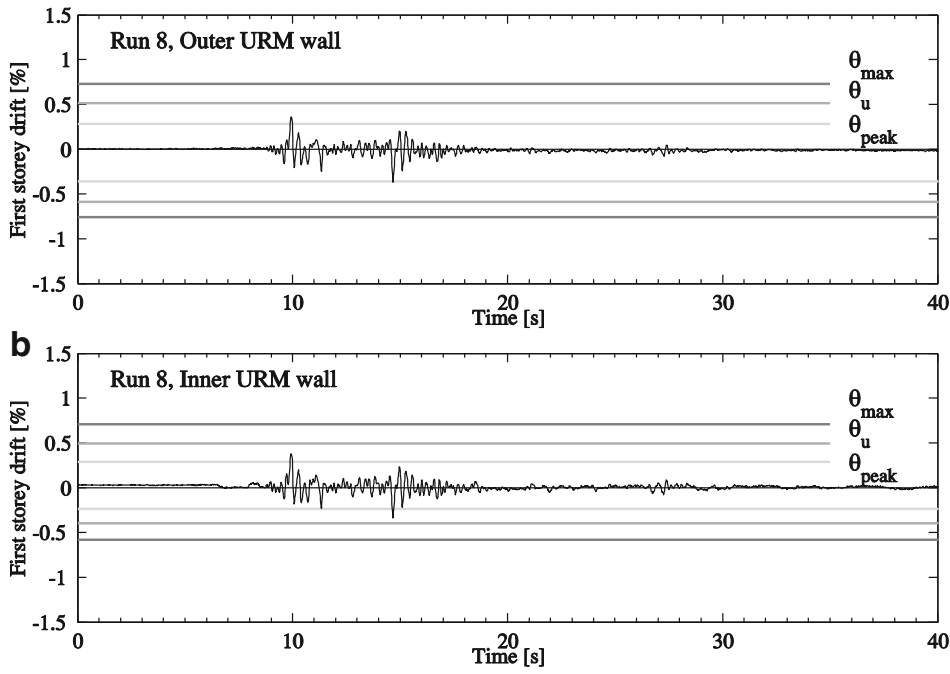

Fig. 12.14 Shake table test, Run 8: comparison of drift histories of first storey walls with drift limits derived from quasi-static cyclic tests
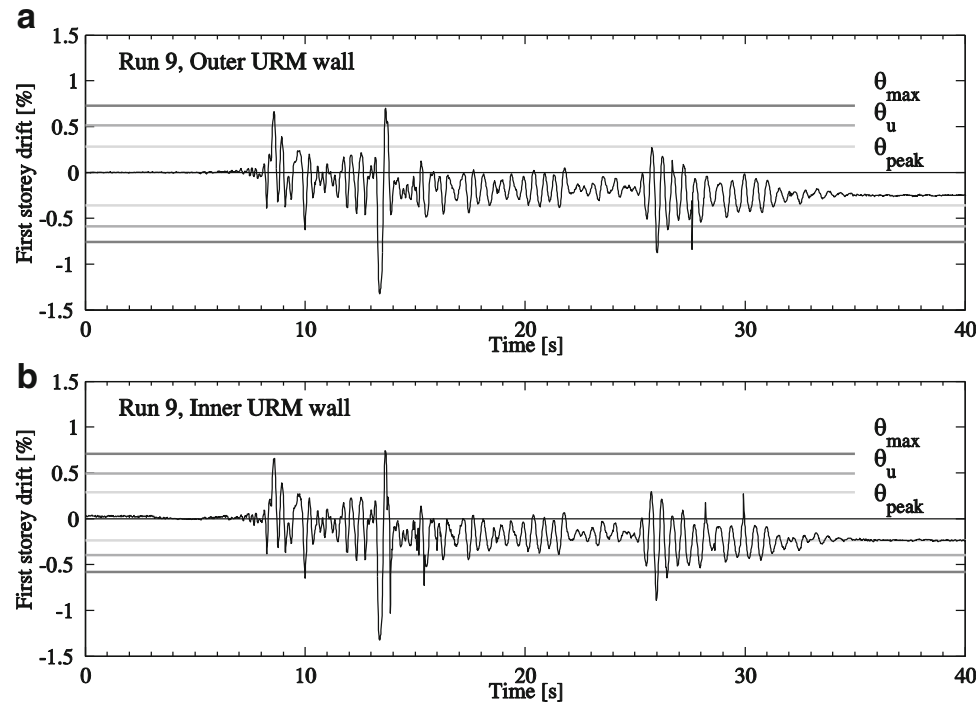

Fig. 12.15 Shake table test, Run 9: comparison of drift histories of first storey walls with drift limits derived from quasi-static cyclic tests 


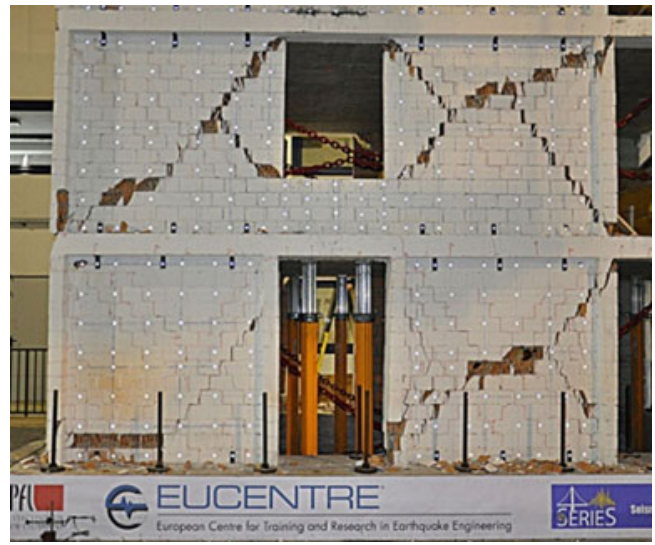

Fig. 12.16 URM walls of shake table test unit after Run 9 (Beyer et al. 2014)

\subsubsection{Conclusions on Comparison of Drift Capacities from Static and Dynamic Tests}

The comparison of drift limits derived from quasi-static cyclic tests with drift histories recorded for a shake table test showed that the former estimate the limit states of the dynamic test rather well. This suggests that the difference in strain rates between quasi-static and dynamic tests does not influence significantly the drift capacities of URM walls associated with different limit states. Hence, the correction factor $\psi_{\mathrm{SR}}$ accounting for strain rate effects should be set to unity. In this study, two limit states could be addressed: The limit state at peak force, which corresponds typically with the onset of localization of the damage in a single crack or row of bricks, and the limit state where the walls lost their axial load bearing capacity.

While the comparison has certain advantages over existing studies comparing the results of static and dynamic tests on URM walls (e.g. same construction material for static and dynamic tests, testing until axial load failure), it still suffers from a number of disadvantages: The size and cross section of the walls subjected to static and dynamic loads was not identical, neither were the boundary conditions the walls were subjected to. In order to investigate strain rate effects systematically, tests at different strain rates using the same test setup should be carried out.

\subsection{Summary and Outlook}

To promote the application of displacement-based approaches for the design of modern URM buildings, reliable estimates of deformation capacities of key structural elements inherent in these buildings are of paramount importance. URM walls, RC slabs and often spandrel elements consisting of a URM spandrel and a strip of the RC slab (referred to as "composite spandrels") are the key elements 
determining seismic vulnerability of URM buildings. Although stiffness and strength of slab and composite spandrels significantly influence the seismic response of these buildings, their deformation capacity is likely to be sufficiently large to be non-critical. The displacement capacity of the building is therefore likely to be controlled by the drift capacity of the first storey URM walls where the shear demand is largest, which is typically determined from empirical equations derived from quasi-static cyclic tests on URM walls.

Recognizing that the accurate estimation of the deformation capacity of URM building elements will lead to displacement-based design approaches that allow to safely and cost effectively design URM buildings, this paper has addressed the influence of the (i) size of the test unit, (ii) loading history, (iii) loading velocity, and (iv) the boundary conditions on the drift capacities of URM walls in the context of results obtained from quasi-static cyclic tests, thereby predicting their true drift limits under earthquake loads. Based on results from 64 monotonic and cyclic tests on URM walls with clay bricks, cement mortar and joints of normal thickness, it was found that the drift capacity decreases with increasing wall height. A drift capacity equation that was recently proposed accounts for this effect as well as the influence of the axial stress ratio and the shear span ratio on the drift capacity of URM walls (Petry and Beyer 2014a, b, c).

Comprehensive studies on the effect of the loading history on URM walls are limited. However, existing studies show that monotonic tests led to drift capacities that were approximately twice as much as those obtained from cyclic tests. Furthermore, load histories commonly applied to quasi-static cyclic tests were too excessive and place much higher demands than those expected for low to moderate seismic earthquakes. This discrepancy in load histories is unlikely to influence the strength of URM walls, but affects their drift capacity. A comparison of response envelopes of first and second cycles of quasi-static cyclic tests of URM walls showed that cumulative damage causes negligible effect on stiffness and strength until a limit state responsible for irreversible wall damage is reached, i.e., onset of crushing of the compression zone or concentration of shear deformations in a single diagonal crack. At the onset of crushing or the concentration of damage in one diagonal crack, the peak force has been attained but not horizontal or axial load failure. Apart from the number of cycles, a potential asymmetry of the boundary conditions (e.g., axial load ratio and shear span ratio) for loading in positive and negative direction can influence the drift capacity. Such conditions are representative for outer walls where slabs and spandrels frame into the wall from only one side of the wall, which can lead to large variations in the axial load of the URM wall under seismic excitation. Since the drift capacity decreases with increasing axial load ratio, the critical loading direction is the one for which the axial load increases. The available experimental data suggest that the drift capacity of a wall subjected to an axial stress ratio three times as high in one direction than in the other is approximately twice that of a wall subjected to large axial forces in both loading directions.

Ideally the effect of the loading velocity should be investigated using the same test setup and loading histories but applying the latter at different speeds as Tomazevic and his co-workers have done it for reinforced masonry developing flexural failure modes (Tomazevic et al. 1996; Tomazevic 2000). Unfortunately for 
URM walls such results are not yet available. To get a first idea, the drift limits obtained from quasi-static cyclic tests were compared to drifts recorded for a 4-storey building tested on a shake table and in general a good agreement was found. To apply the drift limits obtained from quasi-static cyclic tests to the walls in the shake table test unit, a couple of assumptions regarding their axial forces and shear spans were required, which were derived from nonlinear static analysis. Furthermore, the cross section and dimensions of the walls in the shake table test unit and the walls tested quasi-statically were not the same. All walls were, however, constructed using the same type of half-scale bricks and cement mortar.

The results presented in this paper therefore confirm that empirical drift capacity models derived from results of quasi-static cyclic tests can be applied to predict the performance of URM buildings under real earthquake loading - although attention should be paid to the effect of asymmetric boundary conditions of outer piers (captured by the correction factor for the loading history). Future research should, however, also target the development of mechanical drift capacity models as such models will foster the understanding of the behaviour of URM walls, allow to extrapolate with confidence to new configurations of parameters and potentially also allow to develop masonry types with improved performance. For flexural behaviour modes such models have recently been proposed (Priestley et al. 2007; Benedetti and Steli 2006; Petry and Beyer 2014e) but models that address walls developing shear and hybrid modes are currently lacking.

Acknowledgements The shake table test referenced in Sect. 12.4.1 of this paper received funding from the European Community's Seventh Framework Programme [FP7/2007-2013] for access to TREES laboratory of EUCENTRE under the grant agreement $n^{0} 227887$. Additional financial support was received from the Office Fédéral de l'Environnement (OFEV) in Switzerland. The reduced scale bricks were fabricated and donated by Morandi Frères SA, Switzerland. The authors appreciate and gratefully acknowledge all contributions.

Open Access This chapter is distributed under the terms of the Creative Commons Attribution Noncommercial License, which permits any noncommercial use, distribution, and reproduction in any medium, provided the original author(s) and source are credited.

\section{References}

Abrams D (1996) Effects of scale and loading rate with tests on concrete and masonry structures. Earthq Spectra 12(1):13-28

ATC (1997) FEMA-273: NEHRP Guidelines for the seismic rehabilitation of buildings. Basic Procedures Manual. Applied Technology Council (ATC), Washington, DC

ATC (1998) FEMA-306: evaluation of earthquake damaged concrete and masonry wall buildings. Basic Procedures Manual. Applied Technology Council (ATC), Washington, DC

ATC-24 (1992) Guidelines for cyclic seismic testing of components of steel structures for buildings. Applied Technology Council, California

Belmouden Y, Lestuzzi P (2009) An equivalent frame model for seismic analysis of masonry and reinforced concrete buildings. Construct Build Mater 23(1):40-53 
Benaboud H (2013) Effective slab width in URM buildings with RC slabs. M.Sc. Dissertation, EPFL, 2013

Benedetti A, Steli E (2006) Analytical models for shear-displacement curves of unreinforced and FRP reinforced masonry walls. Construct Build Mater 22:175-785

Beyer K, Dazio A (2012) Quasi-static monotonic and cyclic tests on composite spandrels. Earthq Spectra 28(3):885-906

Beyer K, Tondelli M, Petry S, Peloso S (2014) Dynamic testing of a 4-storey building with reinforced concrete and unreinforced masonry walls. Bull Earthquake Eng (submitted)

Braga F, Liberatore D (1990) A finite element for the analysis of the response of masonry buildings. Proceedings of the 5th North American Masonry conference, University of Illinois at Urbana-Champaign

CEN (2005) Eurocode 8: design of structures for earthquake resistance - Part 3: General rules, seismic actions and rules for buildings. Design Code EN 1998-3, European Committee for Standardisation (CEN), Brussels, Belgium

Cervenka V, Jendele L, Cervenka J (2010) Atena - computer program for nonlinear finite element analysis of reinforced concrete structures, Theory and User Manual, Prague, Czech Republic

Chen SY, Moon FL, Yi T (2008) A macroelement for the nonlinear analysis of in-plane unreinforced masonry walls. Eng Struct 30:2242-2252

Da Parè M (2011) The role of spandrel beams on the seismic response of masonry buildings. M.Sc. dissertation, MEEES-ROSE School, Pavia, Italy

DIN (2011) National annex - nationally determined parameters - Eurocode 8: design of structures for earthquake resistance - Part 1: General rules, Seismic actions and rules for buildings. National Annex of Germany, DIN EN 1998-1/NA: 2011-01, Berlin, Germany

Elgawady E, Lestuzzi P, Badoux M (2004) Dynamic versus static cyclic tests of masonry walls before and after retrofitting with GFRP. Proceedings of the 13th world conference on earthquake engineering, Vancouver, Canada

Facconi L, Plizzari G, Vecchio F (2014) Disturbed Stress Field Model for Unreinforced Masonry. J. Struct. Eng., 140(4), 04013085

Fajfar P (1999) Capacity spectrum method based on inelastic demand spectra. Earthquake Eng Struct Dyn 28:979-993

FEMA-461 (2007) Interim protocols for determining seismic performance characteristics of structural and non-structural components through laboratory testing. Federal Emergency Management Agency, Washington, DC

Frumento S, Magenes G, Morandi P, Calvi GM (2009) Interpretation of experimental shear tests on clay brick masonry walls and evaluation of q-factors for seismic design. Technical report, IUSS PRESS, Pavia, Italy

Gambarotta L, Lagomarsino S (1997a) Damage models for the seismic response of brick masonry shear walls. Part I: The mortar joint model and its applications. Earthquake Eng Struct Dyn 26:423-439

Gambarotta L, Lagomarsino S (1997b) Damage models for the seismic response of brick masonry shear walls. Part II: The continuum model and its applications. Earthquake Eng Struct Dyn 26:441-462

Ganz HR, Thürlimann B (1984) Versuche an Mauerwerksscheiben unter Normalkraft und Querkraft. Test Report 7502-4, ETH Zürich, Switzerland, (in German)

Graziotti F (2013) Contributions towards a displacement-based seismic assessment of masonry structures. PhD thesis, Istituto Universitario di Studi Superiori di Pavia, Pavia, Italy

Krawinkler H (2009) Loading histories for cyclic tests in support of performance assessment of structural components. 3rd international conference on advances in experimental structural engineering, San Francisco

Lagomarsino S, Penna A, Galasco A, Cattari S (2013) TREMURI program: an equivalent frame model for the nonlinear seismic analysis of masonry buildings. Eng Struct 56:1787-1799

Lang K (2002) Seismic vulnerability of existing buildings. PhD thesis, ETH Zurich, Zurich, Switzerland 
Lourenço PB (1997) Two aspects related to the analysis of masonry structures: size effect and parameter sensitivity. Technical report TU-DELFT No 03.21.1.31.25, Faculty of Engineering, TU Delft, Delft, The Netherlands

Lourenco PB (2008) Structural masonry analysis: recent developments and prospects. Keynote at the 14th international brick and block masonry conference, Sydney, Australia

Lourenço PB, Rots JG (1997) Multisurface interface model for the analysis of masonry structures. J Eng Mech ASCE 123(7):660-668

Magenes G (2006) Masonry building design in seismic areas: Recent experiences. Keynote at the 1st European conference on earthquake engineering and seismology, Geneva, Switzerland

Magenes G, Calvi GM (1992) Cyclic behaviour of brick masonry walls. Proceedings of the 10th world conference on earthquake engineering, Madrid, Spain

Magenes G, Calvi GM (1997) In-plane seismic response of brick masonry walls. Earthquake Eng Struct Dyn 26:1091-1112

Marino S (2013) Force-deformation characteristics for composite spandrels. M.Sc. Dissertation, EPFL/University of Bologna, Italy

Mergos P, Beyer K (2014) Loading protocols for European regions of low to moderate seismicity. Bull Earthquake Eng online

Milani G (2012) Preface Special Issue: New trends in the numerical analysis of masonry structures. Open Civil Eng J Suppl 1-M1:119-120

Milani G, Lourenço PB, Tralli A (2006a) Homogenised limit analysis of masonry walls, Part I: Failure surfaces. Comput Struct 84(3):166-180

Milani G, Lourenço PB, Tralli A (2006b) Homogenised limit analysis of masonry walls, Part II: Structural examples. Comput Struct 84(3):181-195

MIT (2008) Ministry of Infrastructures and Transportation, Circ. C.S.L1.Pp. No. 617 of 2/2/2009: Istruzioni per l'applicazione delle nuove norme tecniche per le costruzioni di cui al Decreto Ministeriale 14 Gennaio 2008, G.U.S.O. n.27 of 26/2/2009, No. 47, 2008 (in Italian)

Norda H, Butenweg C (2011) Möglichkeiten und Grenzen statisch nichtlinearer Verfahren nach DIN EN 1998-1. Der Bauingenieur 86:S13-S21

NTC (2008) Decreto Ministeriale 14/1/2008: Norme tecniche per le costruzioni. Ministry of Infrastructures and Transportations. G.U.S.O. n.30 on 4/2/2008, 2008 (in Italian)

NZSEE (2006) Assessment and improvement of the structural performance of buildings in earthquakes. New Zealand Society of Earthquake Engineering, University of Auckland, Auckland, New Zealand

NZSEE (2011) Assessment and improvement of unreinforced masonry buildings for earthquake resistance. New Zealand Society of Earthquake Engineering, supplement to "Assessment and improvement of the structural performance of buildings in earthquakes", University of Auckland, Auckland, New Zealand

Paparo A, Beyer K (2014) Quasi-static tests of two mixed reinforced concrete - unreinforced masonry wall structures. Eng Struct online

Paulay T, Priestley MJN (1992) Seismic design of reinforced concrete and masonry buildings. Wiley, New York

Penna A, Lagomarsino S, Galasco A (2013) A nonlinear macroelement model for the seismic analysis of masonry buildings. Earthquake Eng Struct Dyn. doi:10.1002/eqe.2335

Petry S, Beyer K (2014b) Cyclic test data of six unreinforced masonry walls with different boundary conditions. Earthq Spectra (accepted)

Petry S, Beyer K (2014d) Scaling unreinforced masonry for reduced-scale testing. Bull Earthquake Eng online

Petry S, Beyer K (2014a) Influence of boundary conditions and size effect on the drift capacity of URM walls. Eng Struct 65:76-88

Petry S, Beyer K (2014c) Limit states of URM piers subjected to seismic in-plane loading. Bull Earthquake Eng (submitted to VEESD-special issue) 
Petry S, Beyer K (2014e) Review and improvement of simple mechanical models for predicting the force-displacement response of URM piers subjected to in-plane loading. Proceedings of the 2nd European conferences on earthquake engineering and seismology, Istanbul, Turkey

Porter ML (1987) Sequential phased displacement (SPD) procedure for TCCMAR testing. Proceedings of the 3rd meeting of the joint technical coordinating committee on masonry research, US-Japan Coordinated Research Program

Priestley MJN, Amaris AD (2002) Dynamic amplification of seismic moments and shear forces in cantilever walls. Research report ROSE 2002/01, Roseschool, Pavia, Italy

Priestley MJN, Calvi GM, Kowalsky MJ (2007) Displacement-based seismic design of structures. IUSS Press, Pavia, Italy

Salmanpour AH, Mojsilovic N, Schwartz J (2013) Deformation capacity of unreinforced masonry walls subjected to in-plane loading: a state-of-the-art review. Int J Adv Struct Eng 5(1):1-12

SIA (2011) SIA D0237: Evaluation de la sécurité parasismique des bâtiments en maçonnerie. Swiss Society of Engineers and Architects SIA, Zürich, Switzerland (in French)

Snozzi L, Molinari JF (2013) A cohesive element model for mixed mode loading with frictional contact capability. Int J Numer Meth Eng 93:510-526

Tomazevic M (2000) Some aspects of experimental testing of seismic behaviour of masonry walls and models of masonry buildings. ISET J Earthquake Tech 37(4):101-117

Tomazevic M, Lutman M, Petkovic L (1996) Seismic behavior of masonry walls: experimental simulation. J Struct Eng 122:1040-1047

Tondelli M, Petry S, Beyer K, Peloso S (2014) Data set of a shake table test on a four storey structure with reinforced concrete and unreinforced masonry walls. Bull Earthquake Eng (submitted)

Williams D, Scrivener JC (1974) Response of reinforced masonry shear walls to static and dynamic cyclic loading. In: Proceedings of the 5th world conference on earthquake engineering, Rome, Italy

Zucchini A, Lourenço PB (2002) A micro-mechanical model for the homogenisation of masonry. Int J Solid Struct 39:3233-3255 